\title{
Acute hyperglycaemia affects anorectal motor and sensory function in normal subjects
}

\author{
A Russo, W M Sun, Y Sattawatthamrong, R Fraser, M Horowitz, J M Andrews, N W Read
}

\begin{abstract}
Background-The pathogenesis of anorectal dysfunction, which occurs frequently in patients with diabetes mellitus, is poorly defined. Recent studies indicate that changes in the blood glucose concentration have a major reversible effect on gastrointestinal motor function.

Aims-To determine the effects of physiological changes in blood glucose and hyperglycaemia on anorectal motor and sensory function in normal subjects.

Subjects-In eight normal subjects measurements of anorectal motility and sensation were performed on separate days while blood glucose concentrations were stabilised at 4,8 , and $12 \mathrm{mmol} / 1$.

Methods-Anorectal motor and sensory function was measured using a sleevel sidehole catheter incorporating a balloon, and electromyography.

Results-The number of spontaneous anal relaxations was greater at $12 \mathrm{mmol} / \mathrm{l}$ than at 8 and $4 \mathrm{mmol} / 1$ glucose $(p<0.05$ for both). Anal squeeze pressures were less at a blood glucose of $12 \mathrm{mmol} / 1$ when compared with 8 and $4 \mathrm{mmol} / 1 \quad(p<0.05$ for both). During rectal distension, residual anal pressures were not significantly different between the three blood glucose concentrations. Rectal compliance was greater $(p<0.05)$ at a blood glucose of $12 \mathrm{mmol} / 1$ when compared with $4 \mathrm{mmol} / 1$. The threshold volume for initial perception of rectal distension was less at $12 \mathrm{mmol} / 1$ when compared with $4 \mathrm{mmol} / 1$ (40 (20-100) $\mathrm{ml}$ versus $10(10-150) \mathrm{ml}$, p<0.05).
\end{abstract}

Conclusions-An acute elevation of blood glucose to $12 \mathrm{mmol} / 1$ inhibits internal and external anal sphincter function and increases rectal sensitivity in normal subjects. In contrast, physiological changes in blood glucose do not have a significant effect on anorectal motor and sensory function.

(Gut 1997; 41: 494-499)

Keywords: hyperglycaemia; anorectum; motility; sensation; diabetes mellitus

Anorectal dysfunction leading to faecal incontinence occurs in up to $20 \%$ of unselected patients with diabetes mellitus. ${ }^{1-5}$ In diabetic patients with incontinence there are usually multiple anorectal motor and sensory dysfunctions. Internal and external anal sphincter pressures are reduced, ${ }^{24}$ the internal anal sphincter is frequently unstable, ${ }^{6}$ and rectal sensation may be impaired ${ }^{37}$ when compared with healthy subjects. In considering the aetiology of faecal incontinence, it has not been established which is the most important defect. Furthermore, the mechanisms underlying disordered anorectal motor and sensory function in patients with diabetes mellitus are poorly defined.

Recent studies indicate that the blood glucose concentration may have a major, reversible, effect on motor and sensory function in a number of regions of the gastrointestinal tract, both in patients with diabetes mellitus and in normal subjects. ${ }^{8-19}$ Acute changes in the blood glucose concentration affect motility in the oesophagus, ${ }^{8}$ stomach, ${ }^{9-15}$ pylorus, ${ }^{11}$ small intestine, ${ }^{16}{ }^{17}$ gall bladder, ${ }^{18}$ colon, ${ }^{19}$ and anorectum. ${ }^{20}$ For example, gastric emptying is slowed by hyperglycaemia ${ }^{8}$ and accelerated during hypoglycaemia. ${ }^{12}$ Furthermore, changes in the blood glucose concentration within the normal physiological range may affect gastrointestinal motor function. ${ }^{10} 1^{15-23}$ In previous studies of anorectal function in diabetic patients blood glucose concentrations were apparently not monitored, ${ }^{1-467}$ and it is therefore possible that the dysfunctions observed in these patients may, at least in part, have been due to hyperglycaemia per se. Chey et $a l^{20}$ recently evaluated the effect of marked hyperglycaemia (blood glucose approximately $15 \mathrm{mmol} / \mathrm{l}$ ) on anorectal function in normal subjects and reported that both the perception of rectal distension and the rectoanal inhibitory reflex were blunted during hyperglycaemia. These authors did not observe any effect of hyperglycaemia on external or internal anal sphincter function and accordingly suggested that hyperglycaemia did not influence the efferent neural innervation to the anal sphincters. ${ }^{20}$ In their study anal sphincter pressures were evaluated with multiport manometry, rather than a sleeve sensor; the combination of both methods is probably the optimal technique to evaluate external anal sphincter function. ${ }^{24}$ Furthermore, anal sphincter electrical activity was not evaluated. No studies have evaluated the effects of physiological changes in blood glucose on anorectal motility.

We have measured anorectal motor and sensory function in normal subjects using a sleeve/ sidehole catheter and electromyography (EMG), while blood glucose levels were maintained at 4,8 , and $12 \mathrm{mmol} / 1$.
Accepted for publication 10 April 1997 


\section{Materials and Methods}

SUBJECTS

Eight healthy male volunteers (mean age 31 years, range 18-45), were studied. No subject had a history of gastrointestinal or urinary symptoms, or gastrointestinal surgery, or was taking medication. Smoking, caffeine, and alcohol intake were prohibited on the day of each test. Written, informed consent was obtained from each subject and the study protocol was approved by the Human Ethics Committee of the Royal Adelaide Hospital.

\section{MANOMETRIC TECHNIQUE}

The manometric assembly (outer diameter $4.4 \mathrm{~mm}$ ) incorporated eight sideholes, a sleeve sensor, and a $5.5 \mathrm{~cm}$ silicone rubber balloon. Sideholes were located at 1, 2, 3, 4, 8, and $20 \mathrm{~cm}$ and the balloon was located between 10.5 and $16 \mathrm{~cm}$ from the anal verge. The sleeve ( $4 \mathrm{~cm}$ long) was positioned in the anal canal with one end just above the anal verge. ${ }^{24}$ All channels, except the balloon channel, were perfused with degassed distilled water at a rate of $0.5 \mathrm{ml} / \mathrm{min}$ by a pneumohydraulic pump. The channel used to measure intraballoon pressure was water filled, but non-perfused. Balloon distensions with air were performed via a channel located in the centre of the manometric assembly. Two EMG electrodes, incorporated into the back of the sleeve, were used to record myoelectrical activity of both the internal and external anal sphincters. A ground electrode was placed on the subject's right buttock. For measurements of internal anal sphincter activity, a $0.15-3 \mathrm{~Hz}$ frequency range was used, as opposed to $10-500 \mathrm{~Hz}$ for external anal sphincter activity. ${ }^{24}$ Data were recorded using a 12 channel chart recorder (Grass Model E Polygraph, Grass Instruments Co., Quincy, Massachusetts, USA) for manual analysis.

PROTOCOL

In each subject measurements of anorectal motility and sensation were performed on separate days while blood glucose concentrations were maintained at 4,8 , and $12 \mathrm{mmol} / 1$, in single blind fashion, using a glucose clamp technique. ${ }^{25}$ The order of the three studies was randomised. Each study was separated by approximately one week and performed at the same time of the day.

Subjects fasted for at least seven hours and were encouraged to empty their bowels before they arrived in the department. Digital examination was performed to ensure that the rectum was empty. The manometric assembly was introduced along the posterior wall of the anorectum and the subject lay in the left lateral position with the hips flexed at $90^{\circ}$ for the duration of the measurements. Two intravenous cannulae were inserted. One was placed in an antecubital vein of one arm, for intravenous infusion of either $25 \%$ glucose or normal saline. The other was placed in a vein of the contralateral arm for blood sampling. This hand was kept heated, using an electric pad, to arterialise the venous blood. A bolus (adjusted to body weight) of either glucose or saline was given initially, followed by a variable infusion rate, to maintain the desired blood glucose concentration. ${ }^{1125}$ Venous blood glucose concentrations were monitored at least every five minutes using a portable blood glucose meter (Medisense Companion II glucometer, Medisense Inc., Waltman, Massachusetts, USA). The accuracy of these measurements was confirmed subsequently using a hexokinase technique.

Blood glucose concentrations were stabilised at the desired level for 60 minutes before measurements of anorectal motility were started. Anorectal pressures and sphincter electrical activities were initially recorded for 20 minutes under resting conditions. The subject was then instructed to contract the anal sphincter maximally (squeeze) three times, with one minute between each effort. After a further 10 minutes the rectal balloon was serially inflated with 10,20,40,60, 100, and $150 \mathrm{ml}$ of air. ${ }^{26}$ Each inflation was maintained for one minute, and there was a one minute recovery period before the next inflation. The subject was asked to record the occurrence of rectal sensation using an event marker, indicating the onset and duration of the sensation. At the end of each rectal distension the subject was asked to report the nature of the sensation-perception of the balloon, gas (wind), desire to defaecate, discomfort, or pain. ${ }^{26}$ The distension was terminated at a volume of $150 \mathrm{ml}$, or if the subject felt discomfort or pain. After a further five minutes each subject was asked to blow up a party balloon (Ansell International, Glen Waverly, Victoria, Australia) and thus increase the intraabdominal pressure by forced expiration against a resistance. This was repeated three times, separated by one minute. Immediately after this time the intravenous infusion was stopped. Anorectal pressures and blood glucose concentrations were monitored for a further 30 minutes. On the completion of each study (approximately 150 minutes) the subject was given a light meal to prevent hypoglycaemia.

\section{DATA ANALYSIS}

Manometric recordings were analysed manually (without prior knowledge as to whether the study was conducted at 4,8 , or $12 \mathrm{mmol} / \mathrm{l}$ ) for the following parameters. ${ }^{26-29}$

Spontaneous anal relaxations, defined as sustained (greater than 15 seconds duration, greater than $20 \mathrm{~mm} \mathrm{Hg}$ decrease in pressure) reductions in anal pressure, unrelated to straining or any change in rectal pressure. ${ }^{29}$ The number, minimum pressure and duration of each relaxation was recorded for the 20 minute periods at baseline $(60$ minutes after the establishment of the desired blood glucose concentration) and between 10 and 30 mintues after cessation of the intravenous glucose infusion (the last 20 minutes of the study).

The electrical activity of the internal anal sphincter, quantified by counting the number of slow waves before and during each spontaneous anal relaxation. 


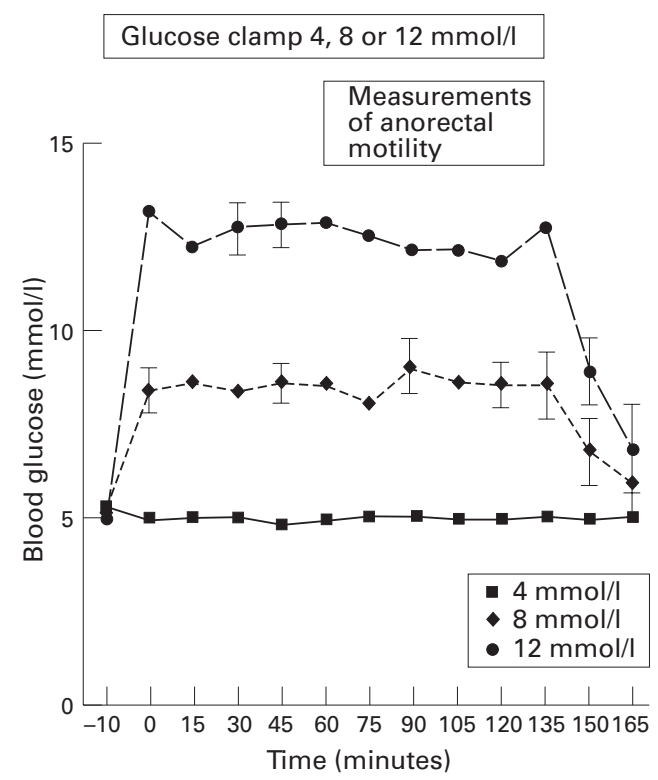

Figure 1: Blood glucose concentrations (mean (SEM)) during the three experiments $(4,8$, and $12 \mathrm{mmol} / \mathrm{l})$.

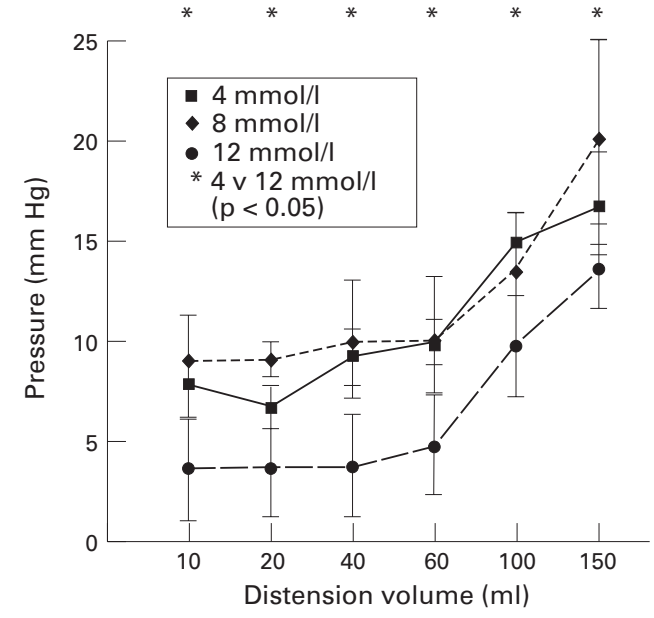

Figure 2: Relation between intraballoon pressure (mean (SEM)) and volume during rectal balloon distension at blood glucose concentrations of 4,8 , and $12 \mathrm{mmol} / \mathrm{l}$.

Minimum basal sleeve pressure, defined as the lowest mean pressure at the end of respiration sustained for at least two minutes during the 20 minute baseline period.

The squeeze plateau pressure, defined as the visual mean of the pressure profile measured using the sleeve sensor. ${ }^{30}$

TABLE 1 Parameters of anorectal motility at blood glucose concentrations of 4, 8 and 12 $\mathrm{mmol} / \mathrm{l}$

\begin{tabular}{|c|c|c|c|}
\hline \multirow[b]{2}{*}{ Parameter } & \multicolumn{3}{|c|}{ Glucose concentration (mmol/l) } \\
\hline & 4 & 8 & 12 \\
\hline \multicolumn{4}{|l|}{ Spontaneous anal relaxations } \\
\hline Number/min & $2(0-5)$ & $3(0-6)$ & $7(3-12)^{\star} \dagger$ \\
\hline Lowest pressure $(\mathrm{mm} \mathrm{Hg})$ & $38(4.5)$ & $29(2.4)$ & $27(2.4)$ \\
\hline Duration (seconds) & $32(3.0)$ & $37(3.9)$ & $34(2.6)$ \\
\hline Minimum basal pressure $(\mathrm{mm} \mathrm{Hg})$ & $54(4.1)$ & $52(3.9)$ & $44(5.9)$ \\
\hline Squeeze pressure (mm Hg) & $162(10.5)$ & $164(8.0)$ & $140(12.1)^{\star} \dagger$ \\
\hline Anal pressure while blowing up a & & & \\
\hline balloon (mm Hg) & $117(13.1)$ & $102(9.7)$ & $88(11.2)^{\star} \dagger$ \\
\hline
\end{tabular}

Results are expressed as mean (SEM), except for number of relaxations. ${ }^{\star} \mathrm{p}<0.05,12 \vee 4 \mathrm{mmol} / \mathrm{l} ; \mathrm{tp}<0.0512 \vee 8 \mathrm{mmol} / \mathrm{l}$.
The plateau anal pressure when the subject was blowing up a party balloon, measured using the sleeve sensor.

The minimum residual anal pressure during rectal balloon distension, defined as the minimum pressure recorded by the sleeve during each rectal distension.

The pressure volume relationship for the balloon. ${ }^{28}$ In this calculation, the pressures in the balloon were corrected for by the pressure elicited by the balloon on serial inflation in the atmosphere.

\section{STATISTICAL ANALYSIS}

Data were evaluated using analysis of variance for repeated measures (ANOVA), the Wilcoxon signed rank test, and Friedman's nonparametric test for repeated measures. Data are presented as mean (SEM) and, when not distributed normally, as median and range. A p value of less than 0.05 was considered to be significant.

\section{Results}

The study protocol was well tolerated by all subjects. Mean blood glucose concentrations closely approximated the desired range (fig 1). In all experiments the blood glucose concentration had returned to the euglycaemic range (4-6 mmol/l) within 10 minutes after cessation of the intravenous infusion.

During the 20 minute baseline period, the number of spontaneous anal relaxations was greater at blood glucose of $12 \mathrm{mmol} / 1$ when compared with both 8 and $4 \mathrm{mmol} / \mathrm{l}$ (table 1 , $\mathrm{p}<0.05$ for both). Spontaneous relaxations were not associated with external sphincter EMG activity, but rather a decrease in internal anal sphincter EMG activity, as demonstrated by a decrease in slow wave frequency (12 $(8-20) / \mathrm{min}$ versus $7 \quad(4-11) / \mathrm{min}, \mathrm{p}<0.05)$. Both the minimum pressure and duration of these spontaneous anal relaxations were not significantly different between the three blood glucose concentrations. Leakage of perfusate did not occur in any subject. In the experiment conducted at a blood glucose of $12 \mathrm{mmol} / \mathrm{l}$ the number of spontaneous anal relaxations during the 20 minute baseline period was greater than the number between 10 and 30 minutes after cessation of the intravenous glucose infusion ( 7 $(3-12) / \mathrm{min}$ versus $0(0-2) / \mathrm{min}, \mathrm{p}<0.05)$. In the latter period (10 to 30 minutes) there was no difference $(p>0.05)$ in the number of spontaneous relaxations between the three experiments $(0(0-4) / \mathrm{min}$ versus $0(0-2) / \mathrm{min}$ and 0 $(0-2) / \mathrm{min}$ respectively for 4,8 , and $12 \mathrm{mmol} /$ 1). There was no difference in the minimum basal pressures between the three blood glucose concentrations (table 1). The mean squeeze pressure in the distal anal canal was lower at a blood glucose concentration of $12 \mathrm{mmol} / 1$ when compared with 8 and $4 \mathrm{mmol} / \mathrm{l}$ (table $1, \mathrm{p}<0.05$ for both). Anal pressures recorded while blowing up a balloon were also less $(p<0.05)$ at a blood glucose of $12 \mathrm{mmol} / 1$ when compared with $4 \mathrm{mmol} / 1$ (table 1).

During rectal distension, the anal pressure decreased $(p<0.05)$ in response to balloon 


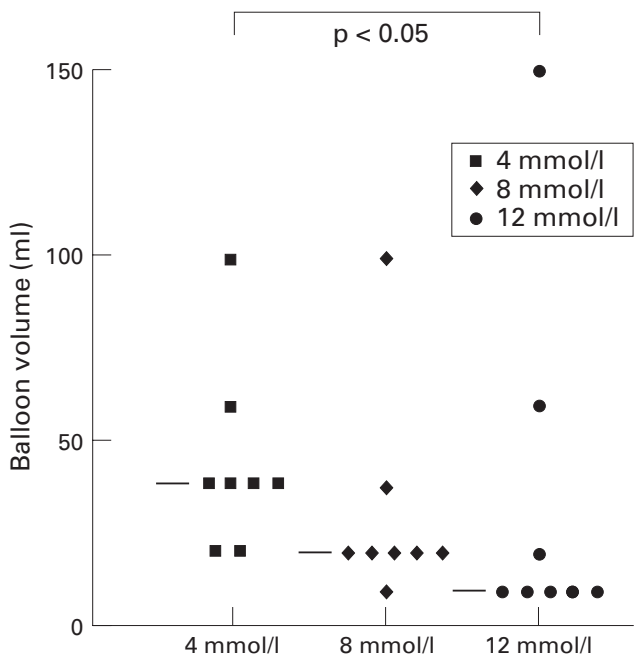

Figure 3: Volume for first perception of sensation during rectal balloon distension at blood glucose concentrations of 4 , 8 , and $12 \mathrm{mmol} / \mathrm{l}$. The median value is shown by the horizontal line.

distension, but there was no significant difference between the three blood glucose concentrations (table 2). Intraballoon pressure increased $(\mathrm{p}<0.05)$ with increasing rectal distending volume. The magnitude of the increase in intraballoon pressure was less $(\mathrm{p}<0.05)$ at $12 \mathrm{mmol} / \mathrm{l}$ when compared with a blood glucose concentration of $4 \mathrm{mmol} / \mathrm{l}$ (fig 2).

Rectal balloon distension was perceived by all subjects. The threshold volume for initial sensation was less $(\mathrm{p}<0.05)$ at a blood glucose of $12 \mathrm{mmol} / 1$ when compared with $4 \mathrm{mmol} / 1$ (fig 3). The threshold volume for desire to defaecate was not significantly different between the three blood glucose concentrations (80 (40-150) $\mathrm{ml}$ versus $70(40-150)$ and 60 (10-150) $\mathrm{ml}$, respectively, for 4,8 , and $12 \mathrm{mmol} / \mathrm{l}$.

\section{Discussion}

This study demonstrates for the first time that acute hyperglycaemia affects internal and external anal sphincter function, as well as rectal sensation and compliance in normal subjects. At a blood glucose concentration of $12 \mathrm{mmol} / \mathrm{l}$ the number of spontaneous anal relaxations was greater, anorectal pressures generated by squeeze and blowing up a balloon were reduced, and both rectal compliance and sensitivity to rectal balloon distension increased when compared with euglycaemia. In contrast, there was no significant effect of changes in blood glucose within the normal postprandial range on anorectal motility or sensation.

TABLE 2 Anorectal motility during rectal distension at blood glucose concentrations of 4, 8 and $12 \mathrm{mmol} / \mathrm{l}$

\begin{tabular}{lllllll}
\hline & \multicolumn{6}{l}{ Rectal distension } \\
\cline { 2 - 6 } & $10 \mathrm{ml}$ & $20 \mathrm{ml}$ & $40 \mathrm{ml}$ & $60 \mathrm{ml}$ & $100 \mathrm{ml}$ & $150 \mathrm{ml}$ \\
\hline Residual anal pressure & $41(6.5)$ & $30(3.0)$ & $35(4.2)$ & $40(5.6)$ & $31(4.1)$ & $30(3.8)$ \\
$\quad 4 \mathrm{mmol} / 1$ & $41(4.7)$ & $35(3.5)$ & $30(3.7)$ & $38(2.6)$ & $36(2.6)$ & $34(3.2)$ \\
$\quad 8 \mathrm{mmol} / 1$ & $30(7.1)$ & $22(5.8)$ & $22(7.0)$ & $27(9.1)$ & $24(8.4)$ & $21(7.6)$ \\
\hline
\end{tabular}

Results are expressed as mean (SEM).
The observed increase in the number of spontaneous transient anal relaxations during hyperglycaemia is indicative of instability of the internal anal sphincter. ${ }^{29}$ We have reported that this phenomenon occurs frequently in diabetic patients with faecal incontinence, and is associated with leakage. ${ }^{6}$ In normal subjects we did not observe leakage of perfusate during internal anal sphincter relaxations because the residual anal pressure was higher than the rectal pressure, associated with compensatory external anal sphincter contraction. However, in diabetic patients the residual anal pressure is lower and compensatory external anal sphincter contraction impaired. ${ }^{6}$ Hence, spontaneous transient anal relaxations are likely to contribute to incontinence. It is not surprising that in diabetic patients faecal incontinence occurs frequently during sleep, when there is no conscious control of anal sphincter function. ${ }^{28}$ The observed increase in rectal compliance during hyperglycaemia is also indicative of smooth muscle inhibition, consistent with the demonstration that acute hyperglycaemia increases proximal gastric compliance in normal subjects. ${ }^{13} 14$

Although the minimum basal anal pressure was not affected by the blood glucose concentration, pressures generated by squeeze and in response to blowing up a balloon were reduced by hyperglycaemia, indicating that hyperglycaemia leads to a reduction in the strength of the external anal sphincter, which would favour incontinence. These findings conflict with those of Chey et $a l^{20}$ who found that hyperglycaemia (blood glucose approximately $15 \mathrm{mmol} / \mathrm{l}$ ) had no effect on maximal squeeze pressure. While there is no clear explanation to account for this discrepancy, there was a modest difference in blood glucose concentrations between the two studies. Furthermore, the sleeve sensor used in our study records the highest pressure along its length, while a simple multiport catheter may fail to record a narrow, high pressure zone. ${ }^{24}$

Our observation that the perception of rectal distension was increased during hyperglycaemia also conflicts with Chey et $a l^{20}$ who reported that hyperglycaemia increased the threshold for initial perception and urge to defaecate. In their study the balloon inflation rate was slower, and a larger diameter $(9 \mathrm{~cm})$ balloon was used. Moreover, measurements of anorectal motility and sensation during hyperglycaemia were compared with "basal" measurements obtained before the induction of hyperglycaemia or euglycaemia hyperinsulinaemia, ${ }^{20}$ thereby introducing the potential for an order effect. To support this approach the authors point out that there is a substantial day to day variability in measures of anorectal motility in normal subjects, which may lead to reduced sensitivity with a paired experimental design. ${ }^{20}$ The rate and frequency of rectal balloon distensions were both relatively high in our study to mimic the rapid arrival of bowel contents, as opposed to evaluation of rectal sensation with a barostat technique which may allow more consistent and potentially unbiased distension. ${ }^{28}$ However, currently available 
barostats do not have the capacity for fast, low volume rectal distensions. Although subjects were unaware of the timing, or volume, of rectal balloon distensions, the order of distensions was not randomised, introducing the potential for response bias. Despite this limitation, our observation of increased gut sensitivity during hyperglycaemia is consistent with other studies. For example, the perception of a number of sensations induced by distension of the proximal stomach, ${ }^{13}{ }^{14}$ oesophagus, ${ }^{21}$ or duodenum ${ }^{31}$ and small intestinal nutrient infusion ${ }^{32}$ is greater during hyperglycaemia than euglycaemia. It is possible that the increase in rectal compliance during hyperglycaemia could lead to the observed increase in rectal sensitivity by increasing the exposure of the in parallel tension receptors in the rectal wall. ${ }^{26}{ }^{28} \mathrm{It}$ remains to be determined whether the effect of hyperglycaemia on rectal sensitivity is also evident in patients with diabetes mellitus, particularly those patients with neuropathy. In particular, in previous studies the threshold for conscious rectal sensation has been reported to be elevated in diabetic patients who had faecal incontinence and evidence of neuropathy, but blood glucose concentrations were not monitored in these studies. ${ }^{3} 7$

We were unable to demonstrate any effect of physiological changes in the blood glucose concentration on anal sphincter function or sensation. An elevation of blood glucose to $8 \mathrm{mmol} / 1$ has been shown to affect motility in the oesophagus, ${ }^{21}$ stomach, ${ }^{15}$ and gall bladder. ${ }^{18}$ While it is possible that a threshold for an effect of hyperglycaemia varies in different regions of the gastrointestinal tract, it is also possible, as discussed previously, that subtle changes were not detected with our study design.

The mechanisms mediating the effects of hyperglycaemia on gastrointestinal motility and sensation are poorly defined but both neural (central, spinal, and peripheral) and hormonal mechanisms are likely to be responsible. A direct effect on smooth muscle is unlikely as both smooth muscle stimulation ${ }^{11}{ }^{17}$ and inhibition ${ }^{1015}$ occur during hyperglycaemia. Hyperglycaemia (blood glucose approximately $15 \mathrm{mmol} / \mathrm{l}$ ) suppresses parasympathetic tone in normal subjects. ${ }^{33}$ Secondary hyperinsulinaemia is unlikely to be primarily responsible for the effects of hyperglycaemia on gastrointestinal motor and sensory function. ${ }^{151920}$ In particular, in other regions of the gut the effects of hyperglycaemia are evident in patients with diabetes mellitus who have no endogenous insulin secretion. ${ }^{10}$ The inhibition of external anal sphincter activity (skeletal muscle) during hyperglycaemia may be secondary to impaired nerve conduction. ${ }^{34}$

While the effects of changes in the blood glucose concentration on anorectal motor function have not yet been evaluated in diabetic patients with and without faecal incontinence, it should be recognised that the observed effects of modifications in the blood glucose concentration on anorectal function in normal subjects mimic a number of the abnormalities reported in diabetic patients with faecal incontinence. ${ }^{6}$ This suggests that optimisation of blood glucose control may be an important component of treatment.

The results of this study have been published in part in abstract form (Gastroenterology 1996; 100: A753). The study was supported by a project grant from the National Health and Medical Research Council of Australia. We wish to thank Mrs S Suter for typing the manuscript and Ms K Wilson for assistance with statistical analysis.

1 Feldman M, Schiller LR. Disorders of gastrointestinal motility associated with diabetes mellitus. Ann Intern Med 1983; 98: 378-84.

2 Schiller LR, Santa Ana CA, Schmulen AC, Hendler RS, Harford WV, Fordtran JS. Pathogenesis of fecal incontinence in diabetes mellitus - evidence for internal-analsphincter dysfunction. $N$ Engl $\mathcal{F}$ Med 1982; 307: 1666-71.

3 Wald A, Tunuguntla K. Anorectal sensorimotor dysfunction in fecal incontinence and diabetes mellitus - modification with biofeedback therapy. N Engl F Med 1984; 310: 1281-7.

4 Rogers J, Levy DM, Henry MM, Misiewicz JJ. Pelvic floor neuropathy: a comparative study of diabetes mellitus and idiopathic fecal incontinence. Gut 1988; 29: 756-61.

5 Wald A. Colonic and anorectal motility testing in clinical practice. Am 7 Gastroenterol 1994; 89: 2109-15.

6 Sun WM, Katsinelos P, Horowitz M, Read NW. Disturbances in anorectal function in patients with diabetes mellitus and faecal incontinence. Eur $\mathcal{F}$ Gastroenterol Hepatol litus and faecal inco

7 Caruana BJ, Wald A, Hinds JP, Eidelman BH. Anorectal sensory and motor function in neurogenic fecal incontinence. Gastroenterology 1991; 100: 465-70.

8 De Boer S, Masclee A, Lam W, Lamers C. Effect of acute hyperglycaemia on oesophageal motility and lower oesophageal sphincter pressure in humans. Gastroenterology 1992; 103: 775-80.

9 Fraser R, Horowitz M, Maddox A, Harding P, Chatterton B, Dent J. Hyperglycaemia slows gastric emptying in type I diabetes mellitus. Diabetologia 1990; 33: 675-80.

10 Barnett J, Owyang C. Serum glucose concentration as a modulator of interdigestive gastric motility. Gastroenterology 1988; 94: 739-44.

11 Fraser R, Horowitz M, Dent J. Hyperglycaemia stimulates pyloric motility in normal subjects. Gut 1991; 31: 475-8.

12 Schvarcz E, Palmer M, Aman J, Lindkvist B, Beckman KW. Hypoglycaemia increases the gastric emptying rate in patients with type I diabetes mellitus. Diabetic Med 1993; 10: $660-3$.

13 Hebbard GS, Sun W-M, Dent J, Horowitz M. Hyperglycaemia affects proximal gastric motor and sensory function in normal subjects. Eur $\mathcal{f}$ Gastroenterol Hepatol 1996; 8: 1-7.

14 Hebbard GS, Samsom M, Sun W-M, Dent J, Horowitz M. Hyperglycaemia affects proximal gastric motor and sensory
function during small intestinal triglyceride infusion. $A m \mathcal{F}$ Physiol 1996; 271: 6814-9.

15 Hasler WL, Soudah HC, Dulai G, Owyang C. Mediation of hyperglycemia-evoked gastric slow-wave dysrhthymias by endogenous prostaglandins. Gastroenterology 1995; 108: 727-36.

16 Bjornsson E, Urbanavicius V, Eliasson B, Attvall S, Smith U, Abrahamasson $\mathrm{H}$. Effects of hyperglycaemia on interdigestive gastrointestinal motility in humans. Scand $\mathcal{F}$ Gastroenterol 1994; 29: 1096-104.

17 Russo A, Fraser R, Horowitz M. The effect of acute hyperglycaemia on small intestinal motility in normal subjects. glycaemia on small intestinal
Diabetologia $1996 ; 39: 984-9$

18 De Boer S, Masclee A, Lam W, Schipper J, Jansen J, Lamers C. Hyperglycemia modulates gallbladder motility and small intestinal transit time in man. Dig Dis Sci 1993; 38: 2228-35.

9 Sims M, Hasler W, Chey W, Kim M, Owyang C. Hyperglycemia inhibits mechanoreceptor-mediated gastrocolonic responses and colonic peristaltic reflexes in healthy humans. Gastroenterology 1995; 108: 350-9.

20 Chey WD, Kim M, Hasler W, Owyang C. Hyperglycemia alters perception of rectal distension and blunts the rectoanal inhibitory reflex in healthy volunteers. Gastroenterology 1995; 108: 1700-8.

21 Boeckxstaens G, Horowitz M, Bermingham H, Holloway RH. Physiological variations in blood glucose concentration affect oesophageal motility and sensation in normal subjects [abstract]. Gastroenterology 1996; 110: A636.

22 Groop LC, De Fronzo R, Luizi L, Melander A. Hyperglycaemia and absorption of sulphonylurea drugs. Lancet 1989; ii: $129-30$.

23 Schuarcz E, Palmer M, Aman J, Horowitz M, Stridsberg M, Berne C. Physiological hyperglycemia slows gastric emptyng in normal subjects and patients with insulin-dependent diabetes mellitus. Gastroenterology 1997; 113: 60-6.

24 Orkin BA, Hanson RB, Kelly KA, Phillips SF, Dent J. Human anal motility while fasting, after feeding, and during sleep. Gastroenterology 1991; 100: 1016-23.

25 DeFronzo RA, Tobin JD, Andres R. Glucose clamp technique: a method for quantifying insulin secretion and resistance. Am f Physiol 1979; 237: E214-23.

26 Sun W-M, Read N, Prior A, Daly J-A, Cheah SK, Grundy D. Sensory and motor responses to rectal distension vary according to rate and pattern of balloon inflation. Gastroenterology 1990; 99: 1008-15. 
27 Sun WM, Donnelly TC, Read NW. Impaired internal anal sphincter in a subgroup of patients with idiopathic faecal incontinence. Gastroenterology 1989; 97: 130-5.

28 Read NW, Sun WM. Anorectal manometry. In: Henry M, Swash M, eds. Coloproctology and pelvic floor. 2nd edn. London: Butterworths, 1992: 119-45.

29 Sun W-M, Read NW, Miner PB, Kerrigan DD, Donnelly TC. The role of transient internal sphincter relaxation in faecal incontinence? Int f Colorect Dis 1990; 5: 31-6.

30 Yeoh EK, Sun WM, Russo A, Ibanez L, Horowitz M. A retrospective study of the effects of pelvic irradiation for gynaecological cancer on anorectal function. Int $\mathcal{f}$ Radiat Oncol Phys 1996; 35: 1003-10.

31 Lingenfelser TH, Sun W-M, Hebbard G, Dent J, Horowitz $M$. Physiological changes in the plasma glucose concentra- tion modify the antropyloroduodenal motor and sensory responses to duodenal distension [abstract]. Gastroenterology 1996; 110: A707.

32 Hebbard GS, Samsom M, Andrews JM, Carman D, Tansell B, Sun WM, et al. Hyperglycemia affects gastric electrical rhythm and nausea during intraduodenal triglyceride infusion. Dig Dis Sci 1977; 42: 568-75.

33 Yeap B, Russo A, Fraser R, Wittert G, Horowitz M. Hyperglycaemia affects cardiovascular autonomic nerve function in normal subjects. Diabetes Care 1996; 19: 880-2.

34 Greene D. A sodium-pump defect in diabetic peripheral nerve corrected by sorbitol administration: relationship to myo-inositol metabolism and nerve conduction slowing. Metabolism 1986; 35: 60-5. 